\title{
ASSESSMENT OF MULTIBEAM BACKSCATTER TEXTURE ANALYSIS FOR SEAFLOOR SEDIMENT CLASSIFICATION
}

\author{
Shahrin Amizul Samsudin and Rozaimi Che Hasan \\ UTM Razak School of Engineering and Advanced Technology, \\ Universiti Teknologi Malaysia, Kuala Lumpur \\ email: shahrinamizul@yahoo.com,rozaimi.kl@utm.my
}

KEY WORDS: Multibeam sonar, Acoustic backscatter, Acoustic classification, Grey Level Co-Occurrence Matrices, image analysis.

\begin{abstract}
:
Recently, there have been many debates to analyse backscatter data from multibeam echosounder system (MBES) for seafloor classifications. Among them, two common methods have been used lately for seafloor classification; (1) signal-based classification method which using Angular Range Analysis (ARA) and Image-based texture classification method which based on derived Grey Level Co-occurrence Matrices (GLCMs). Although ARA method could predict sediment types, its low spatial resolution limits its use with high spatial resolution dataset. Texture layers from GLCM on the other hand does not predict sediment types, but its high spatial resolution can be useful for image analysis. The objectives of this study are; (1) to investigate the correlation between MBES derived backscatter mosaic textures with seafloor sediment type derived from ARA method, and (2) to identify which GLCM texture layers have high similarities with sediment classification map derived from signal-based classification method. The study area was located at Tawau, covers an area of $4.7 \mathrm{~km} 2$, situated off the channel in the Celebes Sea between Nunukan Island and Sebatik Island, East Malaysia. First, GLCM layers were derived from backscatter mosaic while sediment types (i.e. sediment map with classes) was also constructed using ARA method. Secondly, Principal Component Analysis (PCA) was used determine which GLCM layers contribute most to the variance (i.e. important layers). Finally, K-Means clustering algorithm was applied to the important GLCM layers and the results were compared with classes from ARA. From the results, PCA has identified that GLCM layers of Correlation, Entropy, Contrast and Mean contributed to the $98.77 \%$ of total variance. Among these layers, GLCM Mean showed a good agreement with sediment classes from ARA sediment map. This study has demonstrated different texture layers have different characterisation factors for sediment classification and proper analysis is needed before using these layers with any classification technique.
\end{abstract}

\section{INTRODUCTION}

Analysis and determination of physical properties of the seafloor is a crucial element for important marine activities, including coral reef management, fisheries habitat management and marine geology studies (Hedley et al., 2016; BuhlMortensen et al., 2015; Robidoux et al., 2008; Hughes Clarke et al., 1996). Over the last decades, the rapid developments in marine acoustic survey methods have revolutionised the formation of detailed maps of seafloor for the purpose of seabed habitat mapping (Brown et al., 2011b). The use of highresolution acoustic technique, in particular multibeam echosounder system (MBES) in providing full coverage topography (i.e. bathymetry) and acoustic backscatter (i.e. intensity returns) is vital for sediment and habitat types prediction (De Falco et al., 2010; Medialdea et al., 2008; Sutherland et al., 2007). Backscatter returns from MBES is one of the potential dataset from acoustic technique that is seen to consist of important acoustic scattering information of the sediment types and offers huge possibility of remote identification of seafloor as well as proxy for habitat classes.

For sediment classification using backscatter from MBES, image analysis such as the use of image textural analysis is probably the most widely used technique in many studies (Herkül et al., 2017; Lucieer et al., 2016; Blondel et al., 2015; Zhi et al., 2014; Che Hasan, 2014; Hill et al., 2014; Siwabessy et al., 2013; Lucieer et al., 2013; Fakiris et al., 2012; Micallef et al., 2012; Huang et al., 2012; Lucieer et al., 2011; Díaz, 2000). The technique, known as Grey Level Co-Occurrence (GLCM) method originated from textural analysis method of radar image using Haralick textures (Haralick et al., 1973). As many texture layers can be derived from one image (in this case backscatter image), it is important to perform a detail assessment of which texture layers represent sediment classes. This is important because many habitat mapping process such as classification technique requires high spatial resolution data that can be incorporated with high spatial resolution bathymetry maps.

As backscatter data can be also represented by backscatter as a function of incidence angle, some studies have also used angular backscatter intensity (also known as signal-based backscatter) as one of the techniques to extract scattering information (Monteys et al., 2016; Huang et al., 2013; Lamarche et al., 2011; Fonseca et al., 2009; Parnum, 2007). Compared to backscatter image or mosaic, signal-based backscatter from MBES does not have high spatial resolution as the mosaic and thus might not be difficult to be integrated with other high spatial resolution maps such as bathymetry. However, one of the classification methods for signal-based backscatter, known as Angular Range Analysis (ARA) has been developed to automatically predict seafloor sediment types using acoustic inversion process (Fonseca and Mayer, 2007).

Consequently, the objectives of this paper are; (1) to investigate the correlation between MBES derived backscatter mosaic 
texture with seafloor sediment type, and (2) to identify which GLCM texture layers (i.e. from the image-based method) produce sediment classification map that have the highest similarities with signal-based classification method. Figure 2 shown the overall methodology flow chart conducted for this study.

\section{METHODS}

\subsection{Study area}

The study site is located in Tawau, Sabah, Malaysia which covers an area of $4.7 \mathrm{~km}^{2}$. It is situated off the channel in the Celebes Sea between Nunukan Island and Sebatik Island, East Malaysia (Figure 1). The site is adjacent to the international maritime border between Malaysia and Indonesia, located at about $1.5 \mathrm{~km}$ northwest of the Nunukan Island and $2.0 \mathrm{~km}$ southwest of the Sebatik Island. mounted Kongsberg EM2040c multibeam bathymetric system. With a swath of seafloor ensonified four to five times the water depth on each survey line, offset for line spacing is set to three times water depth in order to provide ensonification overlap between adjacent survey lines. The positioning of the vessel during the survey was achieved by using C-Nav3050 DGPS system (horizontal accuracy: $\pm 0.45 \mathrm{~m}+3 \mathrm{ppm}$ and vertical accuracy: $\pm 0.90 \mathrm{~m}+3 \mathrm{ppm}$ ) (Dubilier, 2016), integrated with an Kongsberg Seatex Motion Reference Unit MRU-5 (roll and pitch accuracy: $0.02^{\circ} \mathrm{RMS}$ at a $\pm 5^{\circ}$ amplitude)(Kongsberg, 2016), for roll, pitch and heave corrections. Multibeam data logging, Real-time navigation, display and quality control were using Seafloor Information System (SIS) software version 4.2.1 provided by Kongsberg. A sound velocity profile (SVP) through the water column in the survey area were daily collected in the beginning and at the end of survey process using Valeport

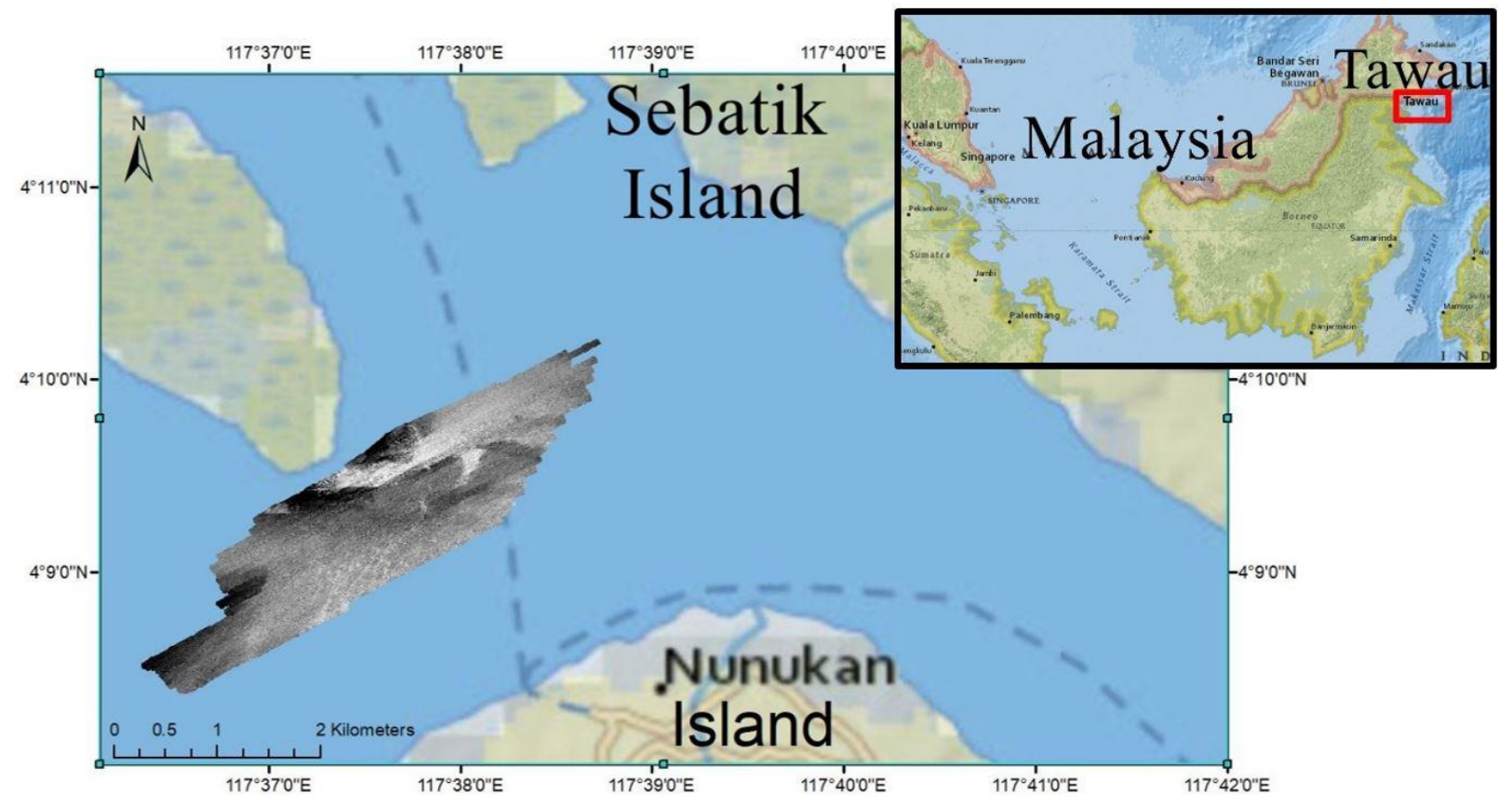

Figure 1: Location map of study area. The inset map shows the location of the study area relative to the location of Malaysia

\subsection{Acoustic data acquisition}

Acoustic data from MBES were acquired on the 26th of November 2017 until 1st of December 2016 using a hull-

\subsection{Acoustic data processing}

Backscatter data can be divided into two formats which are; (1) signal based data or backscatter intensity as a function of incidence angle, and (2) image-based data (i.e. backscatter mosaic). As a result, different classification methods have been established for each dataset (Brown et al., 2011a). The raw MBES backscatter data were processed in Fledermaus Geocoder Toolbox software version 7.4 (FMGT) to obtain (a) backscatter mosaic, and (b) prediction of sediment types using Angular Range Analysis (ARA) technique (Fonseca and Mayer 2007). An automated FMGT processing procedure was applied for both types of backscatter data (Quas et al., 2017). The corrections such as signal level adjustments and transmission loss, beam incidence angle, adjustments of beam footprint area and, Lambertian scattering adjustments were applied for each
Midas SVX2 equipment in order to obtain the speed of sound propagation in the water column at the survey area.

raw backscatter time series beam (QPS, 2016). Next, the backscatter intensity data were filtered based on beam angle , and then an anti-aliasing pass was run on the resulting backscatter swath data (QPS, 2016). For signal based seafloor classification, ARA technique was applied to the angular backscatter intensity to predict sediment types. This process produced estimated bottom sediment map by comparing the angular response/impedance estimates from calibrated backscatter values to empirical sediment models (Fonseca and Mayer 2007). The resulting seafloor characterisation map or ARA map was then exported to raster format for subsequent process. Note that in general, the spatial resolution from ARA map is low, with the size is half of the MBES swath width. Default ARA map yielded 30 sediment classes but then were regrouped to four (4) major sediment classes; sand, silt, clay, and gravel (Figure 3 ) as these classes are the dominant sediment types in ARA map. A set of random point was then generated 
from ARA map to be used as ground truth point. Along with ARA map, a backscatter mosaic image was produced at $1 \mathrm{~m}$ pixel resolution for further analysis. In this study, sampling of ground truth was not available and therefore classes from ARA map were used as known classes to compare results with the classification map produced from texture layers of backscatter mosaic.

\subsection{Derived GLCM and Image Statistics}

Texture from image is an important characteristic for image classification such as used in many terrestrial remote sensing image processing and analysis. Eight (8) Haralick texture layers (Haralick et al., 1973) were derived from backscatter mosaic using ENVI 4.8 software; mean, variance, contrast, correlation, homogeneity, dissimilarity, entropy and angular second moment based on previous literature studies (Herkül et al., 2017; Diesing et al., 2016; Blondel et al., 2015; Lucieer et al., 2013; Huang et al., 2012; Lucieer et al., 2011). All texture layers were derived using Grey Level Co-occurrence Matrix (GLCM) method. GLCM calculates statistics by determining distinctive textural properties from an acoustic image showing the relationships between a given pixel and a specific neighbor (Díaz, 2000). For this study, Haralick texture layers were derived from GLCM calculated for a local rectangular window of $3 \times 3$ pixels.

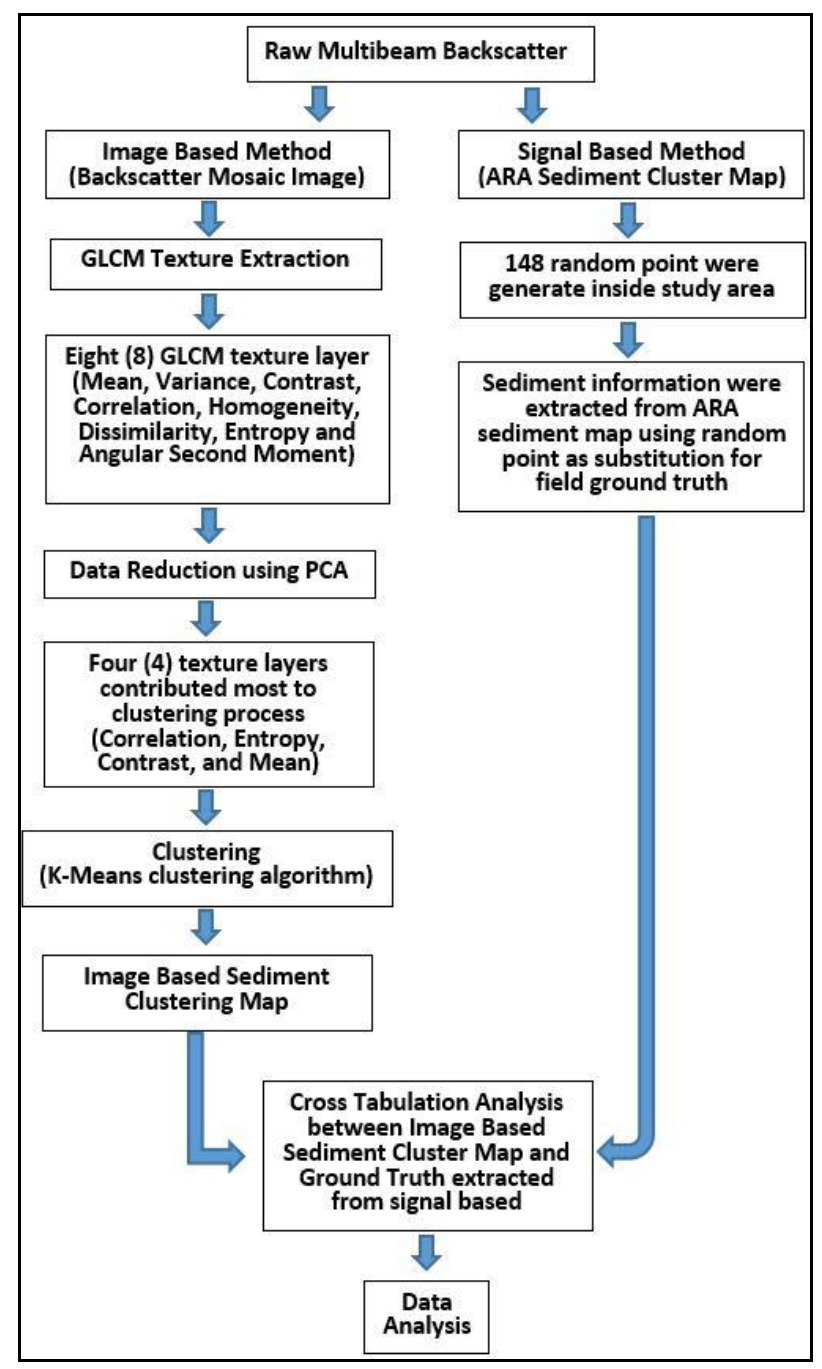

Figure 2: Study Flowchart

\subsection{Principal Component Analysis (PCA)}

Principal Component Analysis (PCA) method has been widely used in the previous study for data reduction and to avoid multicollinearity of the abiotic variables prior to clustering process (Ismail, 2016; Che Hasan, 2014; Verfaillie et al., 2009; Robidoux et al., 2008; Díaz, 2000). PCA has also been used to recognise which textural layers contributing most to the clustering map. PCA computes a set of new and linearly independent variables known as principal components (PCs) that account for most of the variance of the original variables. The PCs are produced from a linear combination of the original variables. PCA was used to determine; (a) which texture layers have the most contributions to the total variance of each rotated PC, and (b) correlations between different texture layers with each PC. Results from this will give a broad idea of which layers are important.

\subsection{Clustering and comparison}

After important texture layers have been identified, a K-Means clustering algorithm was applied to these texture layers. The KMeans clustering technique is widely being used for data segregating for terrestrial remote sensing and also in the marine environment. For this clustering process, the number of the cluster was set to be equal to the number of sediment classes in ARA map (i.e. four classes). A set of 148 points from ARA map were generated by creating random points inside the study area. Cross-tabulations of ground truth and clustered data for four PCs variables resulted from PCA were conducted to compare the occupancy of sediment within each cluster groups.

\section{Results}

The results from PCA analysis produced four (4) PCs, explaining $98.77 \%$ of the total variance. The rotated component matrix (Table 1 and Table 2) shows the correlations between the rotated PCs and the original variables. The main GLCM variables that contributed to the highest variance of the PCA are Correlation (PCA1 -0.49\%), Entropy (PCA1 -0.49\%), Contrast (PCA2 0.57\%), and Mean (PCA3 0.87\%). This four GLCM layer obtained from PCA will be used for next cross tabulation analysis.

\begin{tabular}{|c|c|}
\hline PCA Layer & \% Variance \\
\hline $\mathbf{1}$ & $\mathbf{9 0 . 9 8}$ \\
$\mathbf{2}$ & $\mathbf{5 . 3 5}$ \\
$\mathbf{3}$ & $\mathbf{1 . 6 1}$ \\
4 & 0.83 \\
5 & 0.52 \\
6 & 0.43 \\
7 & 0.22 \\
8 & 0.06 \\
\hline
\end{tabular}

Table 1. The contribution of all principal component analysis (PCA) bands to total variance.

\begin{tabular}{|l|r|r|r|r|r|r|r|r|}
\hline Texture Layer & PCA1 & PCA2 & PCA3 & PCA4 & PCA5 & PCA6 & PCA7 & PCA8 \\
\hline Contrast & -0.22 & $\mathbf{0 . 5 7}$ & 0.07 & 0.03 & 0.47 & -0.03 & -0.15 & -0.61 \\
Correlation & $-\mathbf{0 . 4 9}$ & -0.26 & -0.21 & 0.50 & 0.06 & -0.62 & 0.06 & -0.01 \\
Dissimilarity & -0.30 & 0.41 & -0.02 & -0.09 & 0.38 & 0.03 & 0.08 & 0.76 \\
Entropy & $-\mathbf{0 . 4 9}$ & -0.24 & -0.13 & 0.26 & 0.04 & 0.76 & 0.18 & -0.10 \\
Homogeneity & 0.41 & 0.05 & 0.36 & 0.76 & 0.18 & 0.14 & -0.21 & 0.16 \\
Mean & -0.35 & -0.26 & $\mathbf{0 . 8 7}$ & -0.20 & 0.02 & -0.08 & -0.03 & 0.00 \\
SecondMoment & 0.21 & 0.08 & 0.15 & 0.08 & 0.14 & -0.08 & 0.94 & -0.11 \\
Variance & -0.22 & 0.55 & 0.14 & 0.21 & -0.76 & 0.01 & 0.08 & 0.02 \\
\hline
\end{tabular}


Table 2: Component matrix showing a correlation between rotated PCs and the original variables. Highest factor loads in each PC are highlighted in bold

The results from clustering map showed that, for GLCM Correlation and Entropy layers (Figures 4 and 5), the cluster map only showed two dominant classes. For the Contrast layer, the clustering was also showing poor cluster boundary although successfully produced four classes (Figure 5). Only clustering results from GLCM Mean layer showed cluster map with four classes and well delineated class boundary (Figures 6 and 7).

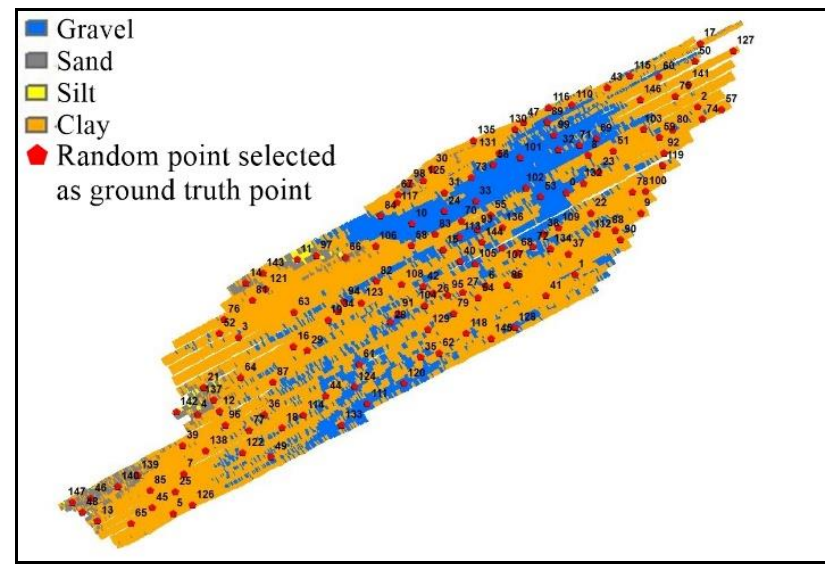

Figure 3: Sediment classes produced using Angular Range Analysis (ARA) and used for ground truthing

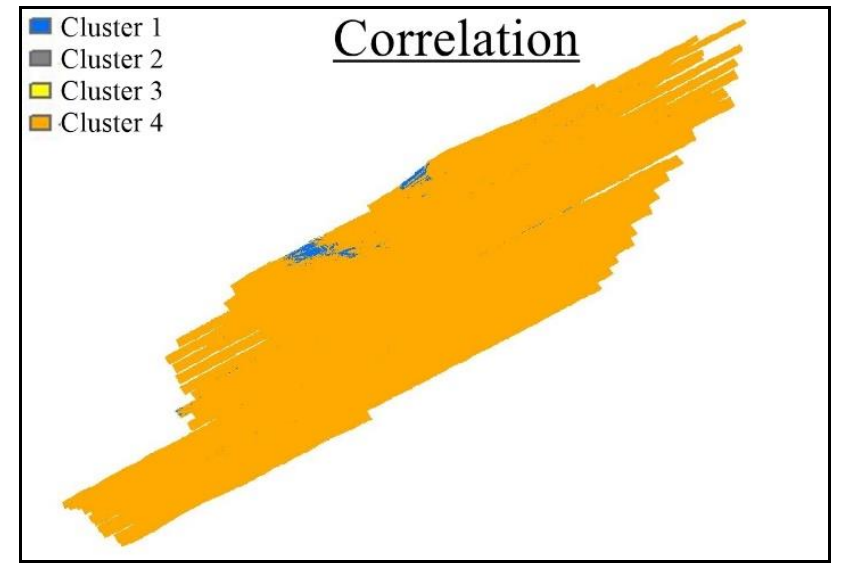

Figure 4: GLCM Correlation Cluster Map

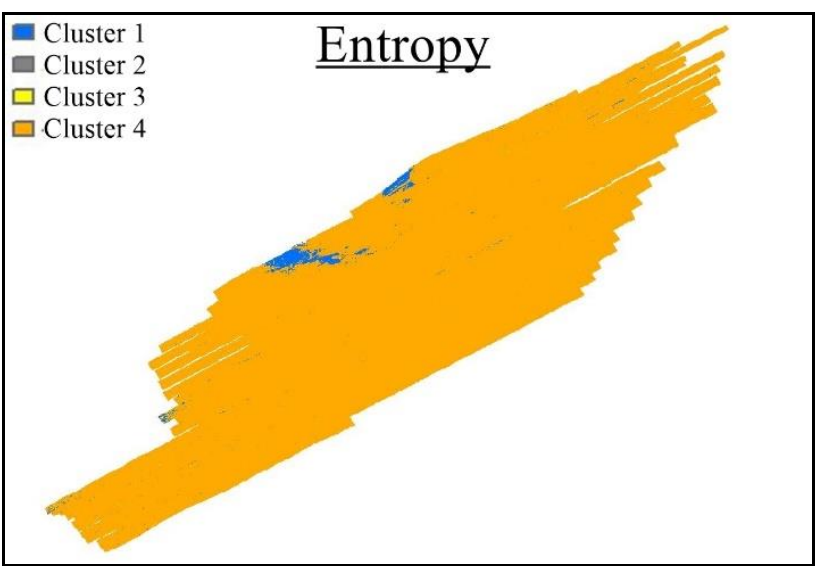

Figure 5: GLCM Entropy Cluster Map

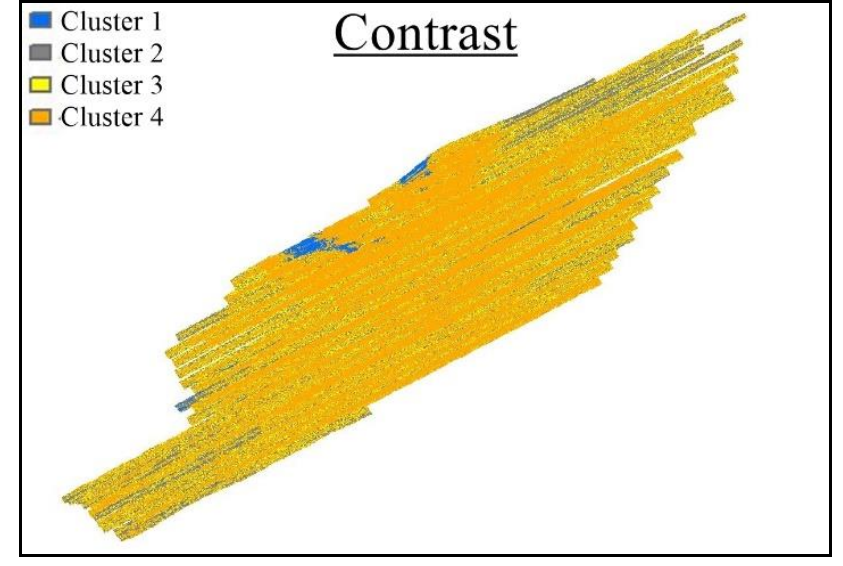

Figure 6: GLCM Contrast Cluster Map

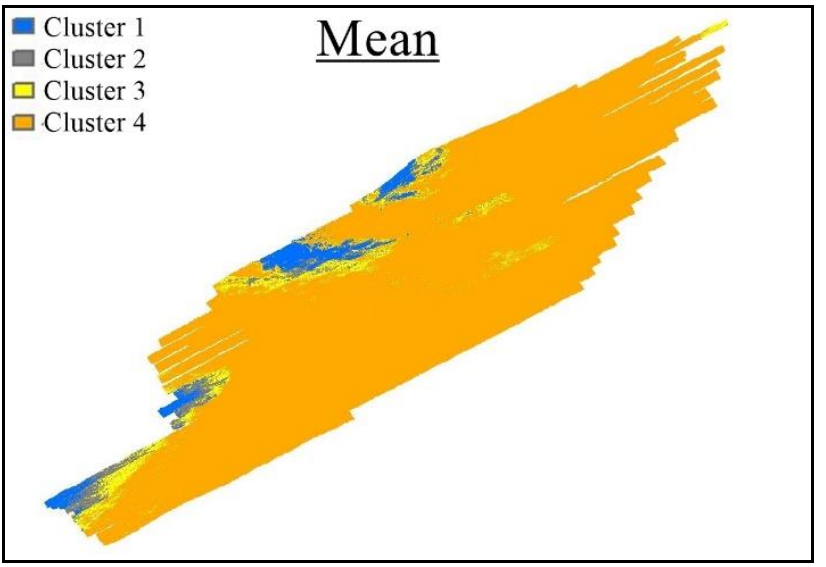

Figure 7: GLCM Mean Cluster Map

Cross tabulation analysis (Tables 3-6 and Figures 8-11) obtained from comparing sediment types and cluster maps in general produced inconsistent results except for GLCM Mean. For GLCM Entropy, only cluster 2 and cluster 4 have strong associations with a specified sediment class. For example, 100\% of cluster 2 was related to Gravel and $67 \%$ of cluster 4 was identified as sand. For GLCM Contrast layer, three different clusters (clusters 2, 3 and 4) in the map showed high agreements with a single sediment type (i.e. sand), at $67 \%, 74 \%$ and $63 \%$ respectively. GLCM Correlation cluster map has identified two clusters with two different sediment types; cluster 1 with silt $(67 \%)$ and cluster 4 with sand $(65 \%)$.

However, for GLCM Mean, each cluster was showing relation to a unique sediment type, although there were some small percentage of other sediment types. For example, cluster 1 with gravel $(42 \%)$, cluster 2 with silt $(83 \%)$, cluster 3 with clay $(43 \%)$ and cluster 4 with sand $(74 \%)$.

\begin{tabular}{|l|c|c|c|c|c|}
\hline $\begin{array}{c}\text { Sediment } \\
\text { Type }\end{array}$ & $\begin{array}{c}\text { Number } \\
\text { of Ground } \\
\text { Truth }\end{array}$ & $\begin{array}{c}\text { Cluster } \\
1(\%)\end{array}$ & $\begin{array}{c}\text { Cluster } \\
2(\%)\end{array}$ & $\begin{array}{c}\text { Cluster } \\
3(\%)\end{array}$ & $\begin{array}{c}\text { Cluster } \\
4(\%)\end{array}$ \\
\hline Gravel & 36 & 17 & 100 & 50 & 24 \\
Sand & 94 & 17 & 0 & 0 & 67 \\
Silt & 13 & 33 & 0 & 50 & 7 \\
Clay & 5 & 33 & 0 & 0 & 2 \\
\hline
\end{tabular}

Table 3: Cross tabulation between the GLCM Entropy cluster map and ground truth observations 


\begin{tabular}{|l|c|c|c|c|c|}
\hline $\begin{array}{c}\text { Sediment } \\
\text { Type }\end{array}$ & $\begin{array}{c}\text { Number } \\
\text { of Ground } \\
\text { Truth }\end{array}$ & $\begin{array}{c}\text { Cluster } \\
1(\%)\end{array}$ & $\begin{array}{c}\text { Cluster } \\
2(\%)\end{array}$ & $\begin{array}{c}\text { Cluster } \\
3(\%)\end{array}$ & $\begin{array}{c}\text { Cluster } \\
4(\%)\end{array}$ \\
\hline Gravel & 36 & 0 & 11 & 23 & 30 \\
Sand & 94 & 0 & 67 & 74 & 63 \\
Silt & 13 & 50 & 19 & 3 & 5 \\
Clay & 5 & 50 & 4 & 0 & 2 \\
\hline
\end{tabular}

Table 4: Cross tabulation between the GLCM Contrast cluster map and ground truth observations

\begin{tabular}{|l|c|c|c|c|c|}
\hline $\begin{array}{c}\text { Sediment } \\
\text { Type }\end{array}$ & $\begin{array}{c}\text { Number } \\
\text { of Ground } \\
\text { Truth }\end{array}$ & $\begin{array}{c}\text { Cluster } \\
1(\%)\end{array}$ & $\begin{array}{c}\text { Cluster } \\
2(\%)\end{array}$ & $\begin{array}{c}\text { Cluster } \\
3(\%)\end{array}$ & $\begin{array}{c}\text { Cluster } \\
4(\%)\end{array}$ \\
\hline Gravel & 36 & 0 & 0 & 0 & 25 \\
Sand & 94 & 0 & 0 & 0 & 65 \\
Silt & 13 & 67 & 0 & 0 & 8 \\
Clay & 5 & 33 & 0 & 0 & 3 \\
\hline
\end{tabular}

Table 5: Cross tabulation between the GLCM Correlation cluster map and ground truth observations

\begin{tabular}{|l|c|c|c|c|c|}
\hline $\begin{array}{c}\text { Sediment } \\
\text { Type }\end{array}$ & $\begin{array}{c}\text { Number } \\
\text { of Ground } \\
\text { Truth }\end{array}$ & $\begin{array}{c}\text { Cluster } \\
1(\%)\end{array}$ & $\begin{array}{c}\text { Cluster } \\
2(\%)\end{array}$ & $\begin{array}{c}\text { Cluster } \\
3(\%)\end{array}$ & $\begin{array}{c}\text { Cluster } \\
4(\%)\end{array}$ \\
\hline Gravel & 36 & 42 & 0 & 14 & 24 \\
Sand & 94 & 8 & 17 & 14 & 74 \\
Silt & 13 & 33 & 83 & 29 & 2 \\
Clay & 5 & 17 & 0 & 43 & 0 \\
\hline
\end{tabular}

Table 6: Cross tabulation between the GLCM Mean cluster map and ground truth observations

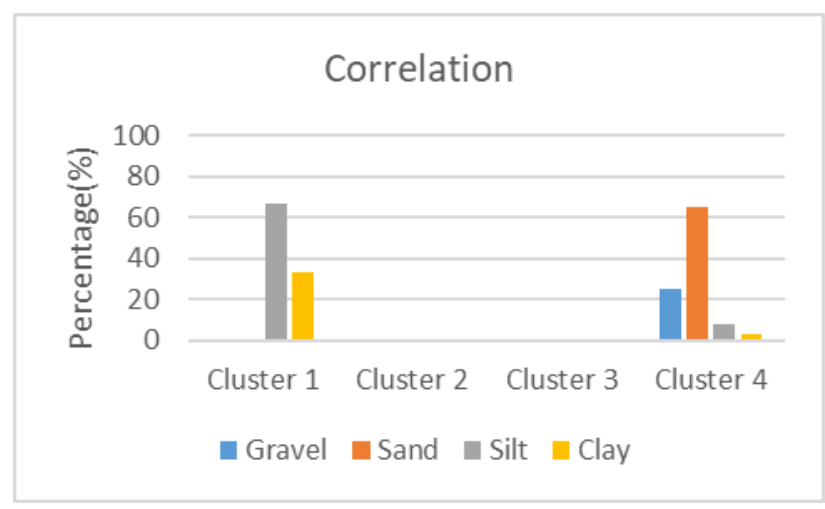

Figure 8: Per cluster sediment composition percentage for GLCM Correlation texture layer

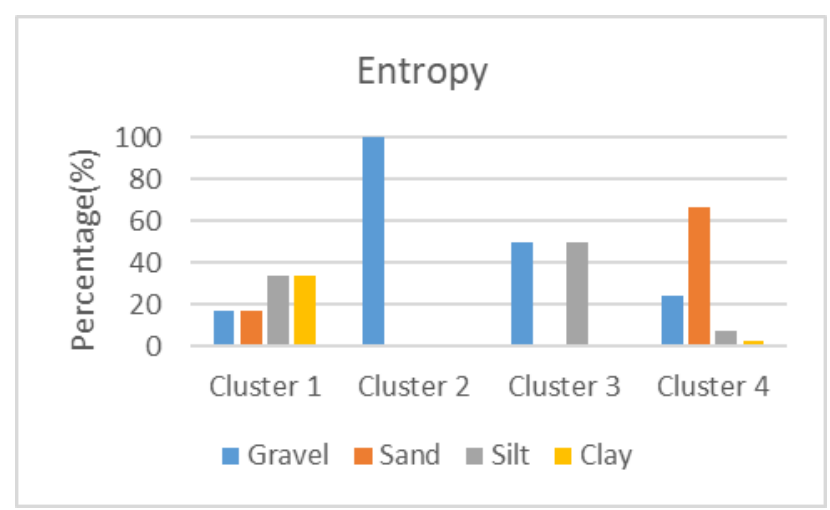

Figure 9: Per cluster sediment composition percentage for GLCM Entropy texture layer

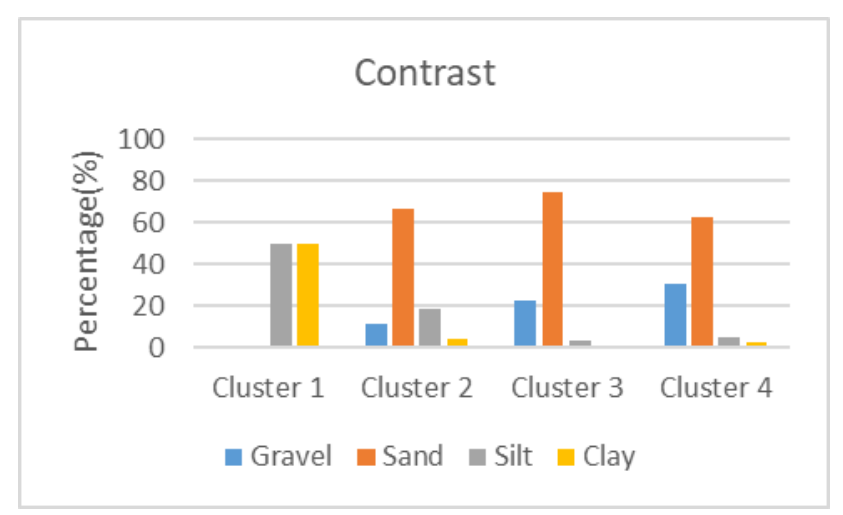

Figure 10: Per cluster sediment composition percentage for GLCM Contrast texture layer

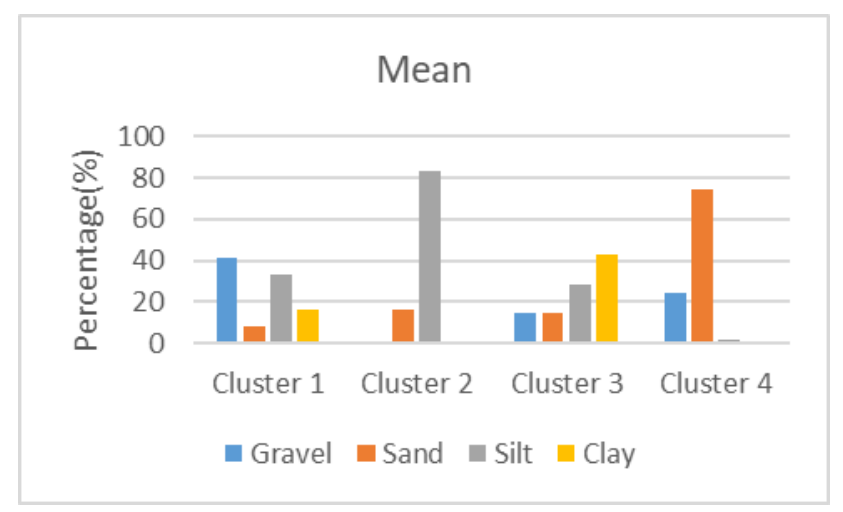

Figure 11: Per cluster sediment composition percentage for GLCM Mean texture layer

\section{DISCUSSION}

The approach of this study is to identify the correlation between MBES derived backscatter mosaic texture with seafloor sediment type and to identify the capability of texture based method to differentiate seafloor sediment classes. The research used sediment classes from ARA as substitute for ground truth and subsequently a set of random ground truth point was generated inside the study area. From the result obtained, it can be clearly seen that only clustering from GLCM Mean layer can provide significant discrimination compare with others three GLCM layers. Previous studies on texture-based sediment classification techniques have shown that the indices 'Mean' capture most of the textural variability within the data (Huvenne et al., 2007). Mean from backscatter has also been used in some of the sediment classification (Hill et al., 2014; Lucieer et al., 2013; Díaz, 2000).

The results from PCA analysis is able to identify some of the important layers in general. Principal component analysis has been broadly used to recognise which textural layers contributing most to the clustering map (Ismail et al., 2015; Che Hasan, 2014; Verfaillie et al., 2009; Robidoux et al., 2008; Díaz, 2000). GLCM Correlation, Entropy, Contrast and Mean are the main texture layer resulted from principal component analysis with percentage eigenvalue more than $1 \%$. However, in this study, the PCA results of identifying the most significant layer disagree with the clustering map analysis. For example, PCA identified GLCM layers of Correlation and Entropy as the most influenced layers (PCA1), but the clustering map analysis has identified different layers (i.e. GLCM Mean). This is due to 
the small ratio of clay and silt within the study area. According to Che Hasan (2014); Müller and Eagles (2007), different sediment proportion within a sediment class also may cause backscatter intensity and texture analysis to diverge and unsupervised classification methods do not allow the control of such factors.

The study identified some relationships between the MBES backscatter mosaic and resulting clusters map with the backscatter derivatives GLCM Mean. Although GLCM Mean at the fourth place in the sequence of most contributing GLCM layer, previous researchers (Che Hasan, 2014) suggested that GLCM mean demonstrates the most significant layer for sediment clustering map.

\section{CONCLUSION}

A total of $4.7 \mathrm{~km}^{2}$ of multibeam sonar backscatter data from Tawau coastal area, Malaysia, was classified using GLCM and K-Means algorithms to find correlations between signal and image based backscatter. Notably, our approach is only using random ground truth point created in GIS software due to limitation during the survey. Hypothetically, if the ground-truth point of the survey had been carried out on a targeted K-Means clustering, the agreement observed may have been more convincing. However, on the basis of the comparisons with randomly created ground-truth data, the cross tabulation analysis conducted has shown encouraging results. In summary, only GLCM Mean texture layer show the significant similarities with signal based sediment classification map and demonstrate the ability to successfully delineating the major type of sediment. Overall, it can be concluded that image-based backscatter classification can assist the interpretation of multibeam backscatter data for the production of sediment maps.

\section{ACKNOWLEDGEMENT}

The authors would like to thank the National Hydrographic Centre (NHC) and the Department of Survey and Mapping Malaysia (DSMM) for the acoustic data collection. Thanks to Universiti Teknologi Malaysia for providing research fund through Research University Grant (RUG) No. Q.K130000.2540.11H41 - 'Acoustic Classification Tool for Automatic Seabed Segmentation'. The authors are also grateful to Acburn Marine Automations Sdn. Bhd. for providing multibeam echosounder system and to all crew from Bot Hidrografi 2 for their help during acoustic data acquisition.

\section{REFERENCES}

Blondel, P., Prampolini, M. \& Foglini, F. (2015). Acoustic textures and multibeam mapping of shallow marine habitatsExamples from Eastern Malta.

Brown, C. J., Smith, S. J., Lawton, P. \& Anderson, J. T. (2011a). Benthic habitat mapping: A review of progress towards improved understanding of the spatial ecology of the seafloor using acoustic techniques. Estuarine, Coastal and Shelf Science, 92, 502-520.

Brown, C. J., Todd, B. J., Kostylev, V. E. \& Pickrill, R. A. (2011b). Image-based classification of multibeam sonar backscatter data for objective surficial sediment mapping of
Georges Bank, Canada. Continental Shelf Research, 31, S110S119.

Buhl-Mortensen, L., Buhl-Mortensen, P., Dolan, M. \& Gonzalez-Mirelis, G. (2015). Habitat mapping as a tool for conservation and sustainable use of marine resources: Some perspectives from the MAREANO programme, Norway. Journal of Sea Research, 100, 46-61.

Che Hasan, R. 2014. Multibeam backscatter for benthic biological habitat mapping. Deakin University.

De Falco, G., Tonielli, R., Di Martino, G., Innangi, S., Simeone, S. \& Parnum, I. M. (2010). Relationships between multibeam backscatter, sediment grain size and Posidonia oceanica seagrass distribution. Continental Shelf Research, 30, 19411950.

Díaz, J. V. M. 2000. Analysis of multibeam sonar data for the characterization of seafloor habitats. University of New Brunswick, Department of Geodesy and Geomatics Engineering.

Diesing, M., Mitchell, P. \& Stephens, D. (2016). Image-based seabed classification: what can we learn from terrestrial remote sensing? ICES Journal of Marine Science, 73, 2425-2441.

Dubilier, N. (2016). Trackline map and processing report for navigation sensors from Meteor M126.

Fakiris, E., Rzhanov, Y. \& Zoura, D. (2012). On importance of acoustic backscatter corrections for texture-based seafloor characterization.

Fonseca, L., Brown, C., Calder, B., Mayer, L. \& Rzhanov, Y. (2009). Angular range analysis of acoustic themes from Stanton Banks Ireland: A link between visual interpretation and multibeam echosounder angular signatures. Applied Acoustics, 70, 1298-1304.

Fonseca, L. \& Mayer, L. (2007). Remote estimation of surficial seafloor properties through the application Angular Range Analysis to multibeam sonar data. Marine Geophysical Researches, 28, 119-26.

Haralick, R. M., Shanmugam, K. \& Dinstein, I. H. (1973). Textural features for image classification. IEEE Transactions on systems, man, and cybernetics, 610-621.

Hedley, J., Roelfsema, C., Chollett, I., Harborne, A., Heron, S., Weeks, S., Skirving, W., Strong, A., Eakin, C., Christensen, T., Ticzon, V., Bejarano, S. \& Mumby, P. (2016). Remote Sensing of Coral Reefs for Monitoring and Management: A Review. Remote Sensing, 8, 118.

Herkül, K., Peterson, A. \& Paekivi, S. (2017). Applying multibeam sonar and mathematical modeling for mapping seabed substrate and biota of offshore shallows. Estuarine, Coastal and Shelf Science, 192, 57-71.

Hill, N. A., Lucieer, V., Barrett, N. S., Anderson, T. J. \& Williams, S. B. (2014). Filling the gaps: Predicting the distribution of temperate reef biota using high resolution biological and acoustic data. Estuarine, Coastal and Shelf Science, 147, 137-147.

Huang, Z., Nichol, S. L., Siwabessy, J. P., Daniell, J. \& Brooke, B. P. (2012). Predictive modelling of seabed sediment 
parameters using multibeam acoustic data: a case study on the Carnarvon Shelf, Western Australia. International Journal of Geographical Information Science, 26, 283-307.

Huang, Z., Siwabessy, J., Nichol, S., Anderson, T. \& Brooke, B. (2013). Predictive mapping of seabed cover types using angular response curves of multibeam backscatter data: Testing different feature analysis approaches. Continental Shelf Research, 61, 12-22.

Hughes Clarke, J. E., Mayer, L. A. \& Wells, D. E. (1996). Shallow-water imaging multibeam sonars: a new tool for investigating seafloor processes in the coastal zone and on the continental shelf. Marine Geophysical Research, 18, 607-629.

Huvenne, V. A., Hühnerbach, V., Blondel, P., Gómez Sichi, O. \& LeBas, T. Detailed mapping of shallow-water environments using image texture analysis on sidescan sonar and multibeam backscatter imagery. Proceedings of the 2nd underwater acoustic measurements conference. Heraklion: FORTH, 2007.

Ismail, K. 2016. Marine landscape mapping in submarine canyons. University of Southampton.

Ismail, K., Huvenne, V. A. I. \& Masson, D. G. (2015). Objective automated classification technique for marine landscape mapping in submarine canyons. Marine Geology, $362,17-32$.

Kongsberg, M. 2016. Data sheet MRU 5 (Ideal Marine Motion Sensor). Norway.

Lamarche, G., Lurton, X., Verdier, A. L. \& Augustin, J. M. (2011). Quantitative characterisation of seafloor substrate and bedforms using advanced processing of multibeam backscatterApplication to Cook Strait, New Zealand. Continental Shelf Research, 31, S93-S109.

Lucieer, V., Hill, N., Barrett, N. \& Nichol, S. Spatial analysis of multibeam acoustic data for the predictiion of marine substrates and benthic communities in temperate coastal waters. ISRSE 2011: International symposium of $\mathrm{R}$ 34th International Symposium on Remote Sensing of Environment, 2011. On USB.

Lucieer, V., Hill, N. A., Barrett, N. S. \& Nichol, S. (2013). Do marine substrates 'look'and 'sound'the same? Supervised classification of multibeam acoustic data using autonomous underwater vehicle images. Estuarine, Coastal and Shelf Science, 117, 94-106.

Lucieer, V., Nau, A. W., Forrest, A. L. \& Hawes, I. (2016). Fine-Scale Sea Ice Structure Characterized Using Underwater Acoustic Methods. Remote Sensing, 8, 821.

Medialdea, T., Somoza, L., León, R., Farrán, M., Ercilla, G., Maestro, A., Casas, D., Llave, E., Hernández-Molina, F. \& Fernández-Puga, M. (2008). Multibeam backscatter as a tool for sea-floor characterization and identification of oil spills in the Galicia Bank. Marine Geology, 249, 93-107.

Micallef, A., Le Bas, T. P., Huvenne, V. A. I., Blondel, P., Hühnerbach, V. \& Deidun, A. (2012). A multi-method approach for benthic habitat mapping of shallow coastal areas with highresolution multibeam data. Continental Shelf Research, 39-40, 14-26.
Monteys, X., Hung, P., Scott, G., Garcia, X., Evans, R. L. \& Kelleher, B. (2016). The use of multibeam backscatter angular response for marine sediment characterisation by comparison with shallow electromagnetic conductivity. Applied Acoustics, $112,181-191$.

Müller, R. D. \& Eagles, S. (2007). Mapping seabed geology by ground-truthed textural image/neural network classification of acoustic backscatter mosaics. Mathematical Geology, 39, 575592.

Parnum, I. M. (2007). Benthic habitat mapping using multibeam sonar systems.

QPS (2016). FMGeocoder Toolbox Online Manual. Fledermaus 7.7.x Documentation.

Quas, L., Church, I., O'Brien, S. J., Wiggert1, J. D. \& Williamson, M. (2017). Application of high-resolution multibeam sonar backscatter to guide oceanographic investigations in the Mississippi Bight.

Robidoux, L., Fonseca, L. \& Wyatt, G. A qualitative assessment of two multibeam echosounder (MBES) backscatter analysis approaches. Canadian Hydrographic Conference and National Surveyors Conference, Thursday, May, 2008.

Siwabessy, P. J. W., Daniell, J., Li, J., Huang, Z., Heap, A. D., Nichol, S., Anderson, T. J. \& Tran, M. 2013. Methodologies for seabed substrate characterisation using multibeam bathymetry, backscatter and video data: A case study from the carbonate banks of the Timor Sea, Northern Australia.

Sutherland, T., Galloway, J., Loschiavo, R., Levings, C. \& Hare, R. (2007). Calibration techniques and sampling resolution requirements for groundtruthing multibeam acoustic backscatter (EM3000) and QTC VIEW ${ }^{\mathrm{TM}}$ classification technology. Estuarine, Coastal and Shelf Science, 75, 447-458.

Verfaillie, E., Degraer, S., Schelfaut, K., Willems, W. \& Van Lancker, V. (2009). A protocol for classifying ecologically relevant marine zones, a statistical approach. Estuarine, Coastal and Shelf Science, 83, 175-185.

Zhi, H., Siwabessy, J., Nichol, S. L. \& Brooke, B. P. (2014). Predictive mapping of seabed substrata using high-resolution multibeam sonar data: A case study from a shelf with complex geomorphology. Marine Geology, 357, 37-52. 